\title{
A Hybrid Stochastic Model of the Budding Yeast Cell Cycle Control Mechanism
}

\author{
Shuo Wang \\ Department of Computer \\ Science \\ Virginia Tech \\ Blacksburg, VA 24061 \\ wangshuo@cs.vt.edu
}

\author{
Mansooreh Ahmadian \\ Department of Computer \\ Science \\ Virginia Tech \\ Blacksburg, VA 24061 \\ amadian@vt.edu
}

\author{
Minghan Chen \\ Department of Computer \\ Science \\ Virginia Tech \\ Blacksburg, VA 24061 \\ cmhshirl@vt.edu
}

\author{
John Tyson \\ Department of Biological \\ Sciences \\ Virginia Tech \\ Blacksburg, VA 24061 \\ tyson@vt.edu
}

\author{
Young Cao \\ Department of Computer \\ Science \\ Virginia Tech \\ Blacksburg, VA 24061 \\ ycao@cs.vt.edu
}

\begin{abstract}
The budding yeast cell cycle is regulated by a complex chemical reaction network. Several deterministic models have been proposed to model this control mechanism. However, experimental data exhibit considerable variability from cell to cell during cell growth and division. It is also observed that certain mutant cells are more vulnerable to noise than wild type cells. The observed variability comes from two sources: intrinsic noise coming from fluctuations of molecules and extrinsic noise introduced by variations in the division process. As a result, molecular fluctuations cannot be neglected, and they may significantly affect the behavior of a cell. To accurately model the cell cycle control mechanism, stochastic models are needed.

A rigorous solution to this problem is to convert a deterministic model to its stochastic equivalent and apply Gillespie's stochastic simulation algorithm (SSA). But the conversion process is not straightforward and often results in a much larger system. Moreover, the high computational cost of Gillespie's algorithm make it difficult to simulate a practical budding yeast cell cycle model. In this manuscript, we present a hybrid (ODE/SSA) stochastic model for the budding yeast cell cycle. Based on error analysis for multiscale systems and the observation that fluctuations of mRNAs are the primary sources of noise, in this hybrid model the dynamics of mRNAs are simulated by Gillespie's algorithm, while the cell cycle mechanism at the protein level is modeled by ordinary differential equations (ODEs). Numerical experiments, implemented by Haseltine and Rawlings' hybrid simulation algorithm, demonstrate that the hybrid
\end{abstract}

Permission to make digital or hard copies of all or part of this work for personal or classroom use is granted without fee provided that copies are not made or distributed for profit or commercial advantage and that copies bear this notice and the full citation on the first page. Copyrights for components of this work owned by others than the author(s) must be honored. Abstracting with credit is permitted. To copy otherwise, or republish, to post on servers or to redistribute to lists, requires prior specific permission and/or a fee. Request permissions from permissions@ acm.org. $B C B^{\prime} 16$, October 2-5, 2016, Seattle, WA, USA.

Copyright is held by the owner/author(s). Publication rights licensed to ACM. ACM 978-1-4503-4225-4/16/10 ...\$15.00.

http://dx.doi.org/10.1145/2975167.2975194. model matches very well with biological experimental data for both wild-type cells and mutant cells in different nutrient media.

\section{Categories and Subject Descriptors}

G.1.7 [Mathematics of Computing]: Numerical Analysis-Ordinary Differential Equations; G.3 [Mathematics of Computing]: Probability and Statistics-Stochastic Processes; I.6.5 [Computing Methodologies]: Simulation and Modeling-Model Development

\section{General Terms}

Algorithms

\section{Keywords}

budding yeast cell cycle model, stochastic simulation algorithm (SSA), hybrid ODE/SSA method

\section{INTRODUCTION}

Budding yeast cells share a number of important features with human cells. Scientists have found that many genes that regulate yeast cell divisions have similar mechanisms with genes that control human cell cycles. Many metabolic and cellular pathways in human cells can be understood through the study of yeast cells. Since yeast cells grow much faster than human cells and are much cheaper to grow in laboratories, they have long been popular model organisms for biological research.

The budding yeast cell cycle is governed by a complex biochemical network of interacting genes and proteins. To study the mechanism of budding yeast cells, several deterministic models have been proposed, ${ }^{3,14,16,17}$ in which the dynamics of all species are modeled using ordinary differential equations (ODEs). However, experimental data exhibit considerable variability from cell to cell during cell growth and division. ${ }^{10,11,15}$ The observed variability is usually attributed to two sources: intrinsic noise from fluctuations of molecule numbers present within a single cell; and extrinsic 
noise from inequalities in sizes of two daughter cell after division. Although the cell cycle is normally robust to environmental perturbations and fluctuations of its species, yeast cells with mutations may become more sensitive to noise. Under the influence of random fluctuations, some mutant cells continue to proliferate, called viable, and others are inviable, failing to exit one of the cell cycle check points. Deterministic models successfully capture the average behavior of wild-type cells. Some of them also provide good predictions for cells with mutations. However, deterministic models do not include noise and cannot be used to model partially viable mutant cells.

In order to rigorously model the effects of noise in the budding yeast cell cycle control mechanism, a deterministic model should be converted into its stochastic equivalent, which employs only elementary reactions. The converted system is suitable for simulation by Gillespie's stochastic simulation algorithm (SSA). ${ }^{5,6}$ However, one of the major difficulties of the conversion lies in those complex phenomenological rate laws, such as Michaelis Menten rate laws or Hill function rate laws. Applying Gillespie's SSA to phenomenological rate laws may generate incorrect stochastic results. Thus we need to unpack these phenomenological rate laws into elementary reactions that are ruled by mass action rate laws. But this practice often results in a much larger system ${ }^{8}$ of reactions and chemical intermediates. On the other hand, low efficiency is a bottleneck of Gillespie's SSA, especially for systems involving multiscale populations and reactions. Since the SSA has to track every reaction event, its computational cost could become unacceptable for practical models. For instance, it took the SSA nearly a week to simulate a complex stochastic model of the budding yeast cell cycle ${ }^{2}$ even though that model does not include mRNA dynamics.

With these challenges in mind, we aim to answer an interesting question: Can we establish a hybrid stochastic model that combines ODEs with the SSA and is complex enough to represent the control mechanism for the budding yeast cell cycle regulation? The goal for the hybrid ODE/SSA model is to accurately model the effect of noise, while the model itself is easy to be generated from a deterministic model.

Fluctuations in species populations can be measured by the coefficient of variation $\left(\mathrm{CV}=\frac{\text { standard deviation }}{\text { mean }}\right)$. An estimation of the $\mathrm{CV}$ for a protein subjected to transcription and translation has been derived by Pedraza and Paulsson ${ }^{12}$

$$
\mathrm{CV}=\sqrt{\frac{1}{N_{p}}+\frac{\tau_{m}}{\tau_{m}+\tau_{p}} \frac{1}{N_{m}}}
$$

where $N_{p}$ and $N_{m}$ are the average molecule numbers of the protein and its corresponding mRNA, $\tau_{p}$ and $\tau_{m}$ are their half-life times, respectively. Given the small volume of a cell, the number of molecules of a particular protein is around hundreds or thousands. However, the population of the mRNA for each protein is normally less than 10 and its half-life time in many cases satisfies $\tau_{p} \leq \tau_{m}$. It leads to a reasonable approximation of $\mathrm{CV}$ as

$$
\mathrm{CV} \approx \sqrt{\frac{1}{2 N_{m}}}
$$

This approximation indicates that fluctuations of mRNAs populations are the primary source of intrinsic noise. Our

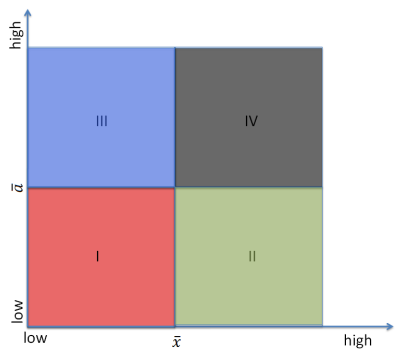

Figure 1: Scales of reactions and populations. Region I contains slow reactions whose reactants have low populations, region II contains slow reactions whose reactants have high populations, region III contains fast reactions whose reactants have low populations, while region IV contains fast reactions whose reactants have high populations.

hybrid ODE/SSA model will take advantage of this observation.

A simple hybrid stochastic cell cycle model was first introduced by Liu et al. ${ }^{9}$ who applied the hybrid modeling idea to Kar et al.'s stochastic model ${ }^{8}$ and simulated the resulting system of equations by a modification of the Haseltine and Rawlings's (HR) hybrid simulation algorithm. ${ }^{7}$ Under the original scheme of the HR hybrid simulation algorithm, a system is partitioned into two groups. The fast reaction group consists of fast reactions whose reactants are of large populations (region IV in Figure 1). The fast reaction group is modeled by ODEs or chemical Langevin equations (CLEs). All remaining reactions, either the reaction is slow or one of the involved species is in a small population (region I, II and III in Figure 1), are put in the slow reaction group, modeled and simulated by the SSA. In Liu et al.'s work, the accuracy and efficiency of the hybrid simulation with different partition strategies were tested. It was discovered that a better partitioning strategy is to only put reactions in Region I, where the reaction is slow and some of its reactants are of small populations, in the SSA regime, while all other reactions in Regions II, III and IV are put into the ODE regime. In particular, Liu et al. ${ }^{9}$ found that all gene expression reactions are partitioned as "slow" reactions and the protein level dynamics are partitioned as "fast" reactions. The hybrid simulation generates reasonably accurate results and saves significant computation time as compared to the full stochastic model. It was then proposed to construct a hybrid stochastic model by adding mRNA dynamics, modeled by the SSA, directly to the deterministic ODE model. This idea of converting a deterministic ODE model into a hybrid stochastic model has been successfully applied to several small biochemical network models. ${ }^{9}$ It remains a question whether this method can be applied to complex biochemical networks, such as the budding yeast cell cycle model. ${ }^{3}$

In this paper we construct a hybrid stochastic model of the budding yeast cell cycle based on Chen et al.'s deterministic model, ${ }^{3}$ which describes the interactions of more than forty species. In our hybrid stochastic model, synthesis and degradation of 19 mRNAs for selected proteins, simulated by the SSA, are added, while interactions of 42 proteins, modeled by ODEs, are derived directly from Chen's model. 
Simulation results are collected for both wild-type cells and mutant cells in different nutrient media and compared with experimental data reported in literature. Details of the hybrid stochastic model and simulation results will be given in this manuscript.

This manuscript is organized as follows. In section $2 \mathrm{im}-$ plementations of the SSA and Haseltine and Rawlings' hybrid method are briefly reviewed. The mechanism of the hybrid stochastic cell cycle model is discussed in detail in section 3 . In section 4 we list the simulation results on wildtype cells and mutant cells in different nutrient media. Conclusion and discussion are given in section 5 .

\section{BACKGROUND}

\subsection{Stochastic Simulation Algorithm}

We consider a well-stirred system of $N$ chemical species $\left\{S_{1}, \ldots, S_{N}\right\}$ and $M$ chemical reactions $\left\{R_{1}, \ldots, R_{M}\right\}$. We define the state of system at $t$ as a vector $\mathbf{x}(t)=\left(x_{1}, \ldots, x_{N}\right)$, where $x_{i}$ is the number of $S_{i}$ molecules. Each reaction channel $R_{j}$ is characterized by its propensity function $a_{j}(\mathbf{x}(t))$ and its state-change vector $\mathbf{v}_{j}=\left(v_{1 j}, \ldots, v_{N j}\right)$. The probability of reaction $R_{j}$ firing in the next infinitesimal time $d t$ is given as $a_{j}(\mathbf{x}(t)) d t$, and $v_{i j} S_{i}$ molecules will be changed by one $R_{j}$ reaction. The procedure of the $\mathrm{SSA}^{5,6}$ is presented as follows.

1) At time $t$, compute the propensity values $a_{j}(\mathbf{x}(t))$, and the sum $a_{0}(\mathbf{x}(t)) \equiv \sum_{j=1}^{M} a_{j}(\mathbf{x}(t))$.

2) Generate a time increment $\tau$ as a sample of the exponential random variable with mean $1 / a_{0}(\mathbf{x}(t))$.

3) Generate a reaction index $j$ based on the probability function $a_{j}(\mathbf{x}(t)) / a_{0}(\mathbf{x}(t))(j=1, \ldots, M)$.

4) Update time $t \leftarrow t+\tau$ and state $\mathbf{x}(t+\tau) \leftarrow \mathbf{x}(t+\tau)+\mathbf{v}_{j}$.

5) Return to step 1) if stopping condition is not reached.

Although the SSA is a fundamental method for stochastic simulation, its computational cost may become very high when the size of a biochemical system increases, since the SSA simulates every reaction event and the time increment $\tau$ often is very small as a consequence of large values of the total propensity $a_{0}(\mathbf{x}(t))$. Thus it is necessary to develop more efficient simulation methods.

\subsection{The Hybrid Method}

The hybrid method presented in this paper was originally proposed by Haseltine and Rawlings. ${ }^{7}$ Given a system of $N$ species $\left\{S_{1}, \ldots, S_{N}\right\}$ and $M$ reactions $\left\{R_{1}, \ldots, R_{M}\right\}$, these $M$ reactions are partitioned into two subsets. Reactions in subset $S_{\text {fast }}$ are formulated by ODEs, and reactions in subset $S_{\text {slow }}$ are simulated by the SSA. Let $a_{j}(\mathbf{x}(t))$ be the propensity function of the $j$-th reaction in $S_{\text {slow }}$, where $\mathbf{x}(t)$ is the state at time $t$, and its state-change vector $\mathbf{v}_{j}=\left(v_{j 1}, \ldots, v_{j N}\right)$. Let $\tau$ be the jump interval of the next slow (stochastic) reaction, and $\mu$ be its reaction index. Set $t=0$. The hybrid method simulates the system as follows:

1) Generate two uniform random numbers $r_{1}$ and $r_{2}$ in $U(0,1)$.
2) Integrate the ODE system and the integral equation:

$$
\int_{t}^{t+\tau} a_{t o t}(\mathbf{x}(s)) d s+\log \left(r_{1}\right)=0,
$$

where $a_{\text {tot }}(\mathbf{x}(t))$ is the sum of propensities of reactions in $S_{\text {slow. }}$.

3) Determine $\mu$ as the smallest integer satisfying

$$
\sum_{i=1}^{\mu} a_{i}(\mathbf{x}(t))>r_{2} a_{t o t}(\mathbf{x}(t)) .
$$

4) Update $\mathbf{x}(t+\tau) \leftarrow \mathbf{x}(t+\tau)+\mathbf{v}_{\mu}$.

5) Return to step 1) if stopping condition is not reached.

Our implementation is different in step 2). Suppose that the ODE system is given by

$$
\mathbf{x}^{\prime}=f(\mathbf{x}) .
$$

We simply add an integration variable $z$ and an equation

$$
z^{\prime}=a_{\text {tot }}(\mathbf{x}), \quad z(t)=\log \left(r_{1}\right)
$$

where we note that $\log \left(r_{1}\right)$ is negative and $a_{t o t}$ is nonnegative. During the simulation, each step starts at time $t$ and numerically integrates ODEs (5) and (6). When $z(t+\tau)=0$, the ODE integration stops, where $\tau$ is the solution to (3). This integration process can be conveniently handled by standard ODE solvers combined with root-finding functions. Note that since $z$ is an integration variable, one may choose to omit it from the error control mechanism. ${ }^{13}$ Adding this extra variable will not greatly affect the efficiency.

\section{METHOD}

Chen et al. constructed a deterministic model of the budding yeast cell cycle, controlled by a complex network of interacting cyclin-dependent protein kinases (CDKs). When CDK activity is low, the yeast cell stays in the G1 phase. At the end of the G1 phase the bud emerges and DNA replication begins. CDK activity rises in S and G2 phases and is destroyed in $M$ phase, when cells exit mitosis and undergo division. Chromosomes are equally separated into two daughter cells. Other components are partitioned more or less evenly to the progeny.

\subsection{The Hybrid Cell Cycle Stochastic Model}

In Chen's model, species are represented in concentrations. The first step to establish a stochastic model is to convert each state variable from concentration to number of molecules. One main reason is that fluctuations of mRNAs need to be simulated by the SSA, which models species with discrete numbers of molecules. The details of the approach are discussed in Ball et al. ${ }^{2}$ Reaction rates and some constants in the Chen et al.'s model are updated so that the dynamics of the transformed system of equations are equivalent to the original model.

In the next step, the synthesis and degradation of mRNAs are added. Reactions related to mRNAs are illustrated in Figure 2. Degradations of mRNAs are easy to implement. Given the half-life time of a mRNA $t_{h}$, its degradation rate $k_{m d}=\ln (2) / t_{h}$. Half-life times of some mRNAs have been estimated from experimental data. ${ }^{1}$ For the other mRNAs, we used $t_{h}=5 \mathrm{~min}$, which is a representative value of reported half-lives. ${ }^{1}$ All the half-life times adopted in this 


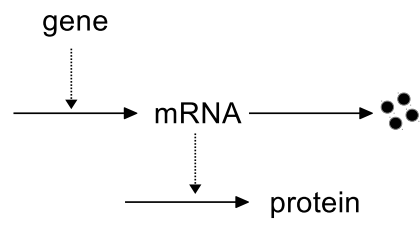

Figure 2: Reactions associated with mRNAs in the hybrid stochastic model.

hybrid model are listed in Table 1 . We set the half-lives of $\mathrm{mNet} 1, \mathrm{mClb} 2$ and $\mathrm{mCln} 2$ to one-half of their experimentally measured values; this change is made so that our hybrid model is more stable and matches better with other experimental results. mRNA synthesis rates, denoted by $k_{m s}$,

Table 1: Half-life Times of mRNAs

\begin{tabular}{|cl|cl|}
\hline mRNA & Model (Expt) & mRNA & Model (Expt) \\
\hline \hline mCdh1 & 5 & mAPC & 5 \\
mTem1 & $5(5)$ & mCln2 & $3(6)$ \\
mCdc15 & $7(7)$ & mClb5 & 5 \\
mCdc14 & 5 & mClb2 & $2(4)$ \\
mNet1 & $8(16)$ & mSic1 & $5(6)$ \\
mCdc55 & 5 & mCdc6 & $5(5)$ \\
mEsp1 & $7(10)$ & mSwi5 & 5 \\
mSBF & 5 & mCdc20 & $5(4)$ \\
mMBF & 5 & mPds1 & 5 \\
mMcm1 & 5 & & \\
\hline
\end{tabular}

are estimated based on degradation rates $k_{m d}$ and the mean values of mRNA molecule numbers $\langle$ mRNA $\rangle$. The mRNAs are divided into two groups: regulated mRNAs and unregulated mRNAs. For an unregulated gene, $k_{m s}$ is chosen so that $\langle\mathrm{mRNA}\rangle=k_{m s} / k_{m d}$ is close to the experimental value of the mean number of mRNA molecules expressed from this gene. For a regulated gene, the total rate of mRNA synthesis is $\sum\left(k_{m s, i} \cdot p_{i}\right)$ where $p_{i}$ are the numbers of protein molecules regulating the gene's expression. The rate constants $k_{m s, i}$ are chosen so that the number of mRNA molecules, averaged over a full cell cycle, is close to the experimentally observed mean number of mRNA molecules in an asynchronous culture. Mean molecule numbers of some mRNAs are reported in Ball's article. ${ }^{1}$ For the other mRNAs, the mean molecule numbers are set to 7 .

Formulas related to protein synthesis are modified to make sure the hybrid model is consistent with the translation processes from mRNAs to proteins. The synthesis of each type of protein in the hybrid model is determined by the number of mRNA. As a result, we replace the terms for protein synthesis in the Chen's model with terms of the form $k_{t} \cdot \mathrm{mRNA}$, where $k_{t}$ is a rate constant for translation of the protein from its specific mRNA molecule.

In a cell cycle, the size of a budding yeast cell increases exponentially before division. How fast a cell grows in biological experiments is measured by the mass doubling time (MDT). Budding yeast cells have different MDTs in different nutrient media: MDT $\approx 90 \mathrm{~min}$ in glucose, MDT $\approx 150$ min in galactose and MDT $\approx 160 \mathrm{~min}$ in raffinose. In our hybrid stochastic model, the cell size (denoted by mass) is controlled by the growth rate $k_{g}=\ln (2) / \mathrm{MDT}$. When a cell exits mitosis, the mass is divided asymmetrically between two daughter cells. The mass for the smaller daughter cell is mass $f$, where $f=\exp \left(-1.026+32 \cdot k_{g}\right)<0.5$ is fitted from experimental data ${ }^{4}$ and the mass for the larger daughter cell is mass $\cdot(1-f)$. In Chen's model, $k_{g}$ is set to $7.702 * 10^{-3}$ for cells in glucose. In our hybrid stochastic model, in order to have better match with experimental data, the value of $k_{g}$ is slightly changed to $7.2 * 10^{-3}$ in glucose and $f$ is set to 0.4 . In raffinose and galactose, $k_{g}$ and $f$ are set the same as in Chen's model.

To simulate the $C L B 2-d b \Delta c l b 5 \Delta$ mutant strain, four basal parameters should be changed. The rate constant $k_{d, b 2}^{\prime \prime}$, associated with the degradation of Clb2 by APC:Cdh1, is set to 0 . The rate constant $k_{d, b 2 p}$, associated with the degradation of Clb2 by APC:Cdc20, is set to 0.075 times the value for the wild-type cell. In this model the dynamics of Clb5 and Clb6 are combined together and represented by Clb5, while the clb5 $\Delta$ mutant only has impact on the dynamics of Clb5. Thus the two rate constants $k_{s, b 5}^{\prime}$ and $k_{s, b 5}^{\prime \prime}$, associated with the synthesis of Clb5 and Clb6, are set to $10 \%$ of corresponding values for the wild-type cell, so that the effect of Clb6 is still maintained in the model.

\subsection{Implementation of The Hybrid Stochastic Simulation}

In order to simulate the growth of cell colonies in different nutrient media, we adopt a special data structure. We use a queue array to record cell id numbers at specified time points. Biochemical states of newborn mother cells and daughter cells are recorded in two queues separately (for the convenience of collecting statistics). The state of a cell is composed of its birth time, its mass and populations of proteins and mRNAs at birth. During the simulation, states of mother cells and daughter cells are popped out from corresponding queues in sequence and used as initial values in the hybrid simulation. If a cell divides successfully before the simulation end time, the cell number increases by one, and the states of two new born cells are pushed into corresponding queues.

In the budding yeast cell cycle model, events are used to specify important checkpoints. When states (populations or concentrations) of certain species increase or decrease across predefined thresholds, corresponding events are triggered. In the deterministic model, an event is triggered only once in one cell cycle. To prevent events from misfiring (being triggered multiple times in a short period of time) due to molecular fluctuations in the hybrid stochastic model, we classify two event patterns in our model: states of certain species change across predefined thresholds in only one direction (increasing or decreasing), or in both directions. For the first type (one direction), we reset the value of thresholds at cell birth time. When simulating a cell cycle, at beginning the thresholds are set to the original predefined values. After an event is triggered, the corresponding threshold is increased to a huge value, for instance 1000 times higher, to prevent misfiring. For the second type (both directions), taking Clb2 as an instance, the solution is illustrated in Figure 3. In Figure 3, events $\mathbf{2}$ and $\mathbf{4}$ are two events in the deterministic model. Events $\mathbf{1}$ and $\mathbf{3}$ are what we add in the hybrid stochastic model. In a cell cycle, events from 1 to 4 are triggered in sequence. Initially, the threshold for event $\mathbf{1}$ is set to $0.5 \mathrm{Kez}$ ( $\mathrm{Kez}$ is a dimensionless concentration unit in the model). After event $\mathbf{i}$ happens, the threshold for $\mathbf{i}$ is 


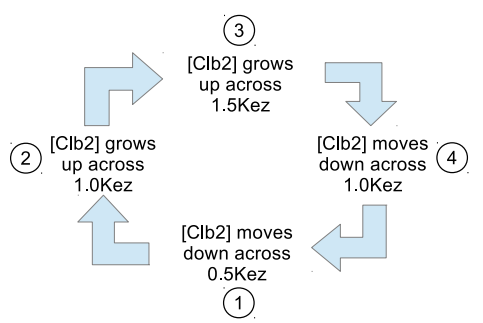

Figure 3: Illustration of the solution to eventhandling related to concentration of Clb2, [Clb2].

set to a huge value and the threshold for event $\mathbf{i}+\mathbf{1}$ is reset to its original predefined value. By applying this tactic, events $\mathbf{2}$ and $\mathbf{4}$ happen in a correct manner in the stochastic simulation, not perturbed by noise of [Clb2].

Numerical simulations are implemented in Fortran. LSODAR is used for the numerical integration of the fast subsystem. LSODAR is an ODE solver based on multistep methods. It can automatically switch between Adams methods for nonstiff problems and BDF methods for stiff problems according to characteristics of the underlying ODEs. LSODAR also provides a root-finding function, which is very convenient for simulating the firing of slow reactions using formula (5) and (6). This feature makes LSODAR much more efficient compared to many other ODE solvers. All the numerical simulations were executed in a Linux workstation with 16G memory and Intel i7-3770 CPU.

\section{RESULTS}

\subsection{Results of Wild-type Cells}

The hybrid stochastic model was simulated for colonies of wild-type cells in different nutrient media: glucose, raffinose and galactose. Oscillations of molecule numbers of three key proteins in glucose are plotted in Figure 4. The simulation

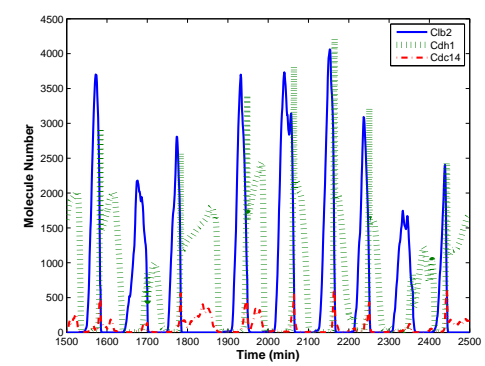

Figure 4: Trajectories of oscillations of protein molecule numbers generated from the hybrid stochastic model in glucose.

results of our hybrid model are compared with experimental data for species' populations reported in literature. Mean molecule numbers of proteins and mRNAs for cells in glucose from simulations and experiments are listed in Table 2 and Table 3. Experimental data of mean molecule numbers of proteins were reported in Di Talia et al. ${ }^{10}$ Experimental data of mean molecule numbers of mRNAs were reported in Ball et al. ${ }^{1}$ Although some mismatches are observed in the two tables, the differences between simulation results and experimental data are reasonable.

Table 2: Average Molecule Numbers of Proteins Compared with Experimental Values

\begin{tabular}{|c|cc|c|cc|}
\hline & Model & Expt & & Model & Expt \\
\hline \hline Cln2 & 1568 & 1500 & Cdc20A & 707 & \\
Clb5 & 538 & 420 & Cdh1T & 2896 & \\
Clb2 & 976 & 650 & Cdh1 & 951 & \\
C2 & 46 & & Tem1 & 719 & 573 \\
C5 & 156 & & Cdc15 & 259 & 238 \\
C2P & 38 & & Cdc14T & 1354 & \\
C5P & 46 & & Cdc14 & 121 & \\
Sic1T & 574 & 788 & Esp1 & 22 & \\
F2 & 21 & & Net1T & 1873 & 1590 \\
F5 & 0.16 & & Net1 & 291 & \\
F2P & 32 & & Cdc55 & 5345 & 5000 \\
F5P & 0.06 & & Pds1 & 29 & \\
Cdc6T & 397 & & APC & 639 & 500 \\
Swi5 & 712 & & Mcm1 & 9325 & 8970 \\
Swi5T & 797 & 688 & SBF & 712 & 590 \\
Cdc20T & 4824 & & MBF & 594 & 520 \\
\hline
\end{tabular}

Statistics of the hybrid stochastic simulations are listed in Table 4 and are compared with experimental data reported in Ball et al. ${ }^{1}$ The distribution of cell cycle periods for wildtype cells in glucose is plotted in Figure 5, which is close to a lognormal distribution. The statistical properties of the hy-

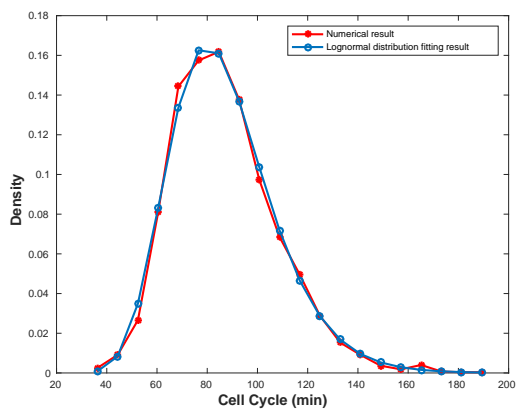

Figure 5: Distribution of cell cycle periods simulated by the hybrid stochastic model in glucose and lognormal distribution fitting result.

brid stochastic model compare favorably with the observed statistics of cell cycle progression in budding yeast cells. For instance, the mean values of three important qualities, $\mathbf{T}_{\mathbf{d i v}}$ (time from birth to division), $\mathbf{T}_{\mathbf{G} \mathbf{1}}$ (time from birth to bud formation) and $\mathbf{V}_{\text {birth }}$ (cell volume at birth) match with experimental data very well (see Table 4). Moreover, the hybrid stochastic model successfully reproduces the effects of noise in the budding yeast cell cycle. CVs generated by the hybrid stochastic model are close to CVs from experimental data. These results support our hypothesis that the primary source of noise in yeast cell cycle progression is molecular fluctuations at the mRNA level.

Number doubling time (NDT) is another important feature for a colony of cells. We simulate wild-type cells growing in three nutrient media. After an initial period, the total number of cells increases exponentially. Denote cell number 
Table 3: Average Molecule Numbers of mRNAs Compared with Experimental Values

\begin{tabular}{|c|cc|c|cc|}
\hline & Model & Expt & & Model & Expt \\
\hline \hline mCdh1 & 6.68 & & mSic1 & 3.79 & 3.34 \\
mTem1 & 2.94 & 3.08 & mCdc6 & 4.88 & 4.07 \\
mCdc15 & 3.11 & 3.24 & mSwi5 & 10.54 & \\
mCdc14 & 10.45 & & mAPC & 6.68 & \\
mNet1 & 5.85 & 6.25 & mCln2 & 5.04 & 4.42 \\
mCdc55 & 6.72 & & mClb5 & 7.85 & \\
mEsp1 & 3.09 & 3.29 & mClb2 & 4.92 & 2.99 \\
mSBF & 6.68 & & mCdc20 & 5.73 & 4.40 \\
mMBF & 6.69 & & mPds1 & 7.28 & \\
mMcm1 & 5.72 & 5.95 & & & \\
\hline
\end{tabular}

by $n$. The value $\log _{10}(n)$ increases approximately linearly with time $t$. The slope for the line is denoted by $a$. The value of $a$ can be estimated through the least square fitting method. NDT is therefore calculated by $\log _{10}(2) / a$. NDTs and MDTs of colonies of cells in three nutrient media are given in Table 5 . We can see that MDT $\approx$ NDT match very well, consistent with observations from biological experiments.

Note that simulations of the hybrid cell cycle model are much faster than simulations with Gillespie's SSA. Our Fortran program which simulates 5,500 cell cycles takes about 400 seconds. The same task executed by the SSA would take several days.

\subsection{Results of Cells with $C L B 2-d b \Delta c l b 5 \Delta$ Mu- tant}

Growth of colonies of $C L B 2-d b \Delta c l b 5 \Delta$ mutant cells were simulated in nutrient media glucose, raffinose and galactose respectively. In Chen's deterministic model, all of the mutant cells under specific growth conditions are either viable or inviable. Biological experiments, however, suggest that mutant cells may be partially inviable under certain growth conditions. The number of cells in a colony may increase exponentially under some circumstances, although NDT of the colony is much smaller than the NDT of wild-type cells growing in the same medium. On the other hand, if more than half of mutant cells exit their cycles, there will be no colony formed (observed).

MDTs and NDTs of colonies of cells are listed in Table 6. MDTs were computed from viable cells in a colony. NDTs were obtained by following the same data fitting method as introduced in previous section. Since the mutant cells do not form a colony in glucose because of the probability that a mutant cell will complete the cell division cycle in glucose is only about $20 \%$, we do not provide results for MDT and NDT in this case. From the table, we can see that the double mutation affects the NDT significantly. NDTs of colonies growing in raffinose and galactose are much longer than MDTs, because of the many inviable cells that do not divide and generate new cells. To measure how the inviable cells affect NDT, $P(T)$, defined as the probability that the cycle time is greater than a specified time, are estimated for colonies in three media. Results are plotted in Figure 6 . In Figure 6, the range of cycle time is from 0 min to $500 \mathrm{~min}$. Cells with cycle times longer than 500 minutes are considered as inviable cells. In every round, about one third

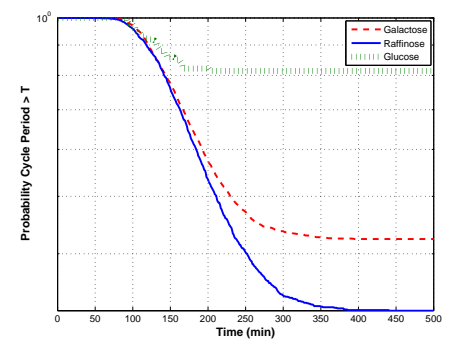

Figure 6: Probability that the cell cycle time is larger than a specified time $T$ for cells with $C L B 2-$ $d b \Delta c l b 5 \Delta$ on three media.

of mutant cells stop cycling in raffinose medium, while forty percent of mutant cells cannot divide in galactose medium. Therefore, the colony in galactose has a much larger NDT.

\section{CONCLUSION AND DISCUSSION}

Many biological experiments have suggested that intrinsic and extrinsic noise could have significant effects on cellular systems. It is important to include noise in mathematical modeling and simulation of biological systems. In this manuscript, we introduce a hybrid stochastic model for the budding yeast cell cycle that is derived from Chen's deterministic model. ${ }^{3}$ In this hybrid ODE/SSA model, synthesis and degradation of mRNAs are simulated by the SSA, while the dynamics of proteins are modeled by ODEs, directly converted from Chen's original model with slight parameter changes. This modeling method and the hybrid stochastic cell cycle model itself have great advantages over traditional stochastic modeling methods. One advantage is that it is not necessary to unpack complex reactions in the deterministic model into elementary reactions, required by Gillespie's SSA framework. This advantage makes the practice of constructing stochastic models much easier than before. The other advantage is that the hybrid stochastic model matches surprisingly well with experimental statistics for budding yeast cells and the simulations run much faster than simulations of its stochastic equivalent. The hybrid stochastic model suggests that the intrinsic noise of the budding yeast cell cycle comes primarily from the stochastic fluctuations of mRNA molecules. Based on formula (2), we hypothesize that this conclusion may also hold for many other cellular systems. For those systems, the strategy of hybrid ODE/SSA modeling and simulation may also be applicable.

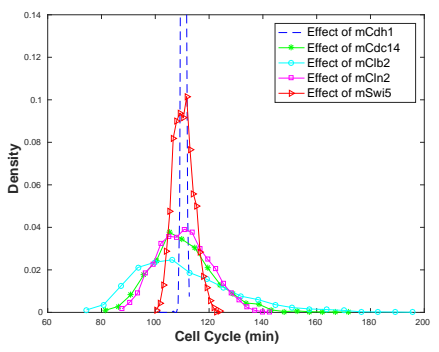

Figure 7: Distributions of cell cycle periods of daughter cells with effects of different mRNAs. 
Table 4: Statistics of Hybrid Stochastic Model Compared with Experimental Values

\begin{tabular}{|c|c|c|c|c|c|c|c|c|}
\hline Quantity & \multicolumn{4}{|c|}{ Mother Cell } & \multicolumn{4}{|c|}{ Daughter Cell } \\
\hline & Mean (model) & Mean (expt) & CV (model & CV (expt) & Mean (model) & Mean (expt) & CV (model) & CV (expt) \\
\hline$\overline{T_{\text {div }}}$ & 87.5 & 87.0 & 0.24 & 0.14 & 111.5 & 112.0 & 0.26 & 0.22 \\
\hline $\mathbf{T}_{\mathrm{G} 1}$ & 20.9 & 16.9 & 0.31 & 0.50 & 33.8 & 37.0 & 0.50 & 0.50 \\
\hline $\mathbf{V}_{\text {birth }}$ & 41.8 & 40.0 & 0.24 & 0.18 & 27.9 & 28.0 & 0.24 & 0.22 \\
\hline
\end{tabular}

Table 5: MDTs and NDTs of Colonies of Wild-type Cells in Three Media

\begin{tabular}{|c|ccc|}
\hline & Glucose & Raffinose & Galactose \\
\hline MDT & 90 & 153 & 166 \\
NDT & 95 & 149 & 162 \\
\hline
\end{tabular}

Table 6: MDTs and NDTs of Colonies of CLB2$d b \Delta c l b 5 \Delta$ Cells in Two Media

\begin{tabular}{|l|cc|}
\hline & Raffinose & Galactose \\
\hline MDT & 170 & 162 \\
NDT & 356 & 662 \\
\hline
\end{tabular}

In our hybrid ODE/SSA model, the stochastic dynamics of all mRNAs are considered. To measure the effect of noise introduced by each mRNA, simulations are carried out in which the synthesis and degradation of only one mRNA species are simulated by SSA, and the distributions of cell cycle times are generated. Through our analysis of these simulations, we find that mRNAs do not contribute equally to the effects of noise. Some mRNAs, such as the mRNAs encoding Cdc14, Clb2 and Cln2, have much greater impact on the entire system. Distributions of cell cycle times are close to lognormal distributions. Interestingly, distributions of cell cycle times with respect to those mRNAs with greater impact have relatively larger variances (see Figure 7). The large variances may be explained by the greatly delayed synthesis of some proteins and may result in the high sensitivity of mutant cells. In the near future, we will take efforts to analyze the mechanism of the hybrid model to uncover how the noise of different mRNAs affect the entire network.

\section{ACKNOWLEDGMENTS}

This work was partially supported by the National Science Foundation under awards DMS-1225160, CCF-0953590, CCF1526666, and MCB-1613741.

\section{REFERENCES}

[1] D. A. Ball, N. R. Adames, N. Reischmann, D. Barik, C. T. Franck, and J. J. Tyson. Measurement and modeling of transcriptional noise in the cell cycle regulatory network. Cell Cycle, 12(19):3203-3218, October 2013.

[2] D. A. Ball, T.-H. Ahn, P. Wang, K. C. Chen, Y. Cao, J. J. Tyson, J. Peccoud, and W. T. Baumann. Stochastic exit from mitosis in dudding yeast. Cell Cycle, 10(6):999-1009, March 2011.
[3] K. C. Chen, L. Calzone, A. Csikasz-Nagy, F. R. Cross, B. Novak, and J. J. Tyson. Integrative analysis of cell cycle control in budding yeast. Molecular Biology of the Cell, 15:3841-3862, August 2004.

[4] K. C. Chen, A. Csikasz-Nagy, B. Gyorffy, J. Val, B. Novak, and J. J. Tyson. Kinetic analysis of a molecular model of the budding yeast cell cycle. Molecular Biology of The Cell, 11(1):369-391, Jan 2000.

[5] D. T. Gillespie. A general method for numerically simulating the stochastic time evolution of coupled chemical reactions. Journal of Computational Physics, 22(4):403-434, 1976.

[6] D. T. Gillespie. Exact stochastic simulation of coupled chemical reactions. Journal of Physical Chemistry, 81(25):2340-2361, 1977.

[7] E. L. Haseltine and J. B. Rawlings. Approximate simulation of coupled fast and slow reactions for stochastic chemical kinetics. Journal of Chemical Physics, 117(15):6959-6969, October 2002.

[8] S. Kar, W. T. Baumann, M. R. Paul, and J. J. Tyson. Exploring the roles of noise in the eukaryotic cell cycle. PNAS, 106(16):6471-6476, April 2009.

[9] Z. Liu, Y. Pu, F. Li, C. A. Shaffer, S. Hoops, J. J. Tyson, and Y. Cao. Hybrid modeling and simulation of stochastic effects on progression through the eukaryotic cell cycle. Journal of Chemical Physics, 136(3), January 2012.

[10] S. Di Talia, J. M. Skotheim, J. M. Bean, E. D. Siggia, and F. R. Cross. The effects of molecular noise and size control on variablility in the budding yeast cell cycle. nature, 448:947-952, August 2007.

[11] M. Miyata, M. Miyata, and M. Ito. The cell cycle in the fission yeast, schizosaccharomyces prombe. i. relationship between cell size and cycle time. Cell Structure and Function, 3(1):39-46, 1978.

[12] J. M. Pedraza and J. Paulsson. Effects of molecular memory and bursting on fluctuations in gene expression. Science, 319:339-343, 2008.

[13] L. R. Petzold. A description of dassl: A differential/algebraic system solver. In The IMACS World Congress, volume 1, page 65, September 1982.

[14] Z. Qu, J. N. Weiss, and W. R. MacLellan. Regulation fo the mammalian cell cycle: a model of the g1-to-s transition. American Journal of Physiology-Cell Physiology, 284(2):C349-C364, 2003.

[15] J. J. Tyson. The coordination of cell growth and division-intentional or incidental? BioEssays, 2:72-77, February 1985.

[16] J. J. Tyson. Modeling the cell division cycle: Cdc2 and cyclin interactions. PNAS, 88(16):7328-7332, August 1991. 
[17] J. J. Tyson and B. Novak. Temporal organization of the cell cycle. Current Biology, 18(17):R759-R768, September 2008.

\section{APPENDIX}

\section{A. ODES AND REACTIONS OF THE HY- BRID STOCHASTIC MODEL}

In this hybrid stochastic cell cycle model, the temporal evolution of cell mass and of forty two proteins are modeled by ODEs, which are listed below.

$$
\begin{aligned}
& \frac{\mathrm{d} \text { mass }}{\mathrm{dt}}=k_{g} \cdot \text { mass } \\
& \frac{\mathrm{d} \operatorname{Cln} 2}{\mathrm{dt}}=k_{s, n 2} \cdot \mathrm{mCln} 2 \cdot \operatorname{mass}-k_{d, n 2} \cdot \mathrm{Cln} 2+k_{g} \cdot \mathrm{Cln} 2 \\
& \frac{\mathrm{d} \mathrm{Clb} 5}{\mathrm{dt}}=k_{s, b 5} \cdot \mathrm{mClb} 5 \cdot \operatorname{mass}+\left(k_{d 3, c 1} \cdot \mathrm{C} 5 \mathrm{P}+k_{d i, b 5}\right. \\
& +\left(k_{d 3, f 6} \cdot \mathrm{F} 5 \mathrm{P}+k_{d i, f 5} \cdot \mathrm{F} 5\right) \\
& -\left(V_{d, b 5}+k_{a s, b 5} \cdot \frac{\mathrm{Sic} 1}{\mathrm{mass}}+k_{a s, f 5} \cdot \frac{\mathrm{Cdc} 6}{\mathrm{mass}}\right) \cdot \mathrm{Clb} 5 \\
& +k_{g} \cdot \mathrm{Clb} 5 \\
& \frac{\mathrm{d} \mathrm{Clb} 2}{\mathrm{dt}}=k_{s, b 2} \cdot \mathrm{mClb} 2 \cdot \operatorname{mass}+\left(k_{d 3, c 1} \cdot \mathrm{C} 2 \mathrm{P}+k_{d i, b 2} \cdot\right. \\
& +\left(k_{d 3, f 6} \cdot \mathrm{F} 2 \mathrm{P}+k_{d i, f 2} \cdot \mathrm{F} 2\right) \\
& -\left(V_{d, b 2}+k_{a s, b 2} \cdot \frac{\mathrm{Sic} 1}{\mathrm{mass}}+k_{a s, f 2} \cdot \frac{\mathrm{Cdc} 6}{\mathrm{mass}}\right) \cdot \mathrm{Clb} 2 \\
& +k_{g} \cdot \mathrm{Clb} 2 \\
& \frac{\mathrm{d} \mathrm{Sic} 1}{\mathrm{dt}}=k_{s, s 1} \cdot \mathrm{mSic} 1+\left(V_{d, b 2}+k_{d i, b 2}\right) \cdot \mathrm{C} 2 \\
& +\left(V_{d, b 5}+k_{d i, b 5}\right) \cdot \mathrm{C} 5+k_{p p, c 1} \cdot \frac{\mathrm{Cdc} 14 \cdot \operatorname{Sic} 1 \mathrm{P}}{\operatorname{mass}} \\
& -\left(k_{a s, b 2} \cdot \frac{\mathrm{Clb} 2}{\operatorname{mass}}+k_{a s, b 5} \cdot \frac{\mathrm{Clb} 5}{\operatorname{mass}}+V_{k p, c 1}\right) \cdot \operatorname{Sic} 1 \\
& +k_{g} \cdot \operatorname{Sic} 1 \\
& \frac{\mathrm{d} \operatorname{Sic} 1 \mathrm{P}}{\mathrm{dt}}=V_{k p, c 1} \cdot \operatorname{Sic} 1-\left(k_{p p, c 1} \cdot \frac{\mathrm{Cdc} 14}{\operatorname{mass}}+k_{d 3, c 1}\right) \cdot \operatorname{Sic} 1 \mathrm{P} \\
& +V_{d, b 2} \cdot \mathrm{C} 2 \mathrm{P}+V_{d, b 5} \cdot \mathrm{C} 5 \mathrm{P}+k_{g} \cdot \mathrm{Sic} 1 \mathrm{P} \\
& \frac{\mathrm{d} \mathrm{C} 2}{\mathrm{dt}}=k_{a s, b 2} \cdot \frac{\mathrm{Clb} 2 \cdot \mathrm{Sic} 1}{\mathrm{mass}}+k_{p p, c 1} \cdot \frac{\mathrm{Cdc} 14 \cdot \mathrm{C} 2 \mathrm{P}}{\operatorname{mass}} \\
& -\left(k_{d i, b 2}+V_{d, b 2}+V_{k p, c 1}\right) \cdot \mathrm{C} 2+k_{g} \cdot \mathrm{C} 2 \\
& \frac{\mathrm{d} \mathrm{C} 5}{\mathrm{dt}}=k_{a s, b 5} \cdot \frac{\mathrm{Clb} 5 \cdot \mathrm{Sic} 1}{\mathrm{mass}}+k_{p p, c 1} \cdot \frac{\mathrm{Cdc} 14 \cdot \mathrm{C} 5 \mathrm{P}}{\operatorname{mass}} \\
& -\left(k_{d i, b 5}+V_{d, b 5}+V_{k p, c 1}\right) \cdot \mathrm{C} 5+k_{g} \cdot \mathrm{C} 5 \\
& \frac{\mathrm{d} \mathrm{C} 2 \mathrm{P}}{\mathrm{dt}}=V_{k p, c 1} \cdot \mathrm{C} 2-\left(k_{p p, c 1} \cdot \frac{\mathrm{Cdc} 14}{\operatorname{mass}}+k_{d 3, c 1}+V_{d, b 2}\right) \cdot \mathrm{C} 2 \mathrm{P} \\
& +k_{g} \cdot \mathrm{C} 2 \mathrm{P} \\
& \frac{\mathrm{d} \mathrm{C} 5 \mathrm{P}}{\mathrm{dt}}=V_{k p, c 1} \cdot \mathrm{C} 5-\left(k_{p p, c 1} \cdot \frac{\mathrm{Cdc} 14}{\operatorname{mass}}+k_{d 3, c 1}+V_{d, b 5}\right) \cdot \mathrm{C} 5 \mathrm{P} \\
& +k_{g} \cdot \mathrm{C} 5 \mathrm{P} \\
& \frac{\mathrm{d} \operatorname{Cdc} 55}{\mathrm{dt}}=k_{s, p p x} \cdot \operatorname{mass} \cdot \operatorname{mCdc} 55-V_{d, p p x} \cdot \operatorname{Cdc} 55+k_{g} \cdot \operatorname{Cdc} 55 \\
& \frac{\mathrm{d} \mathrm{Cdc} 6 \mathrm{P}}{\mathrm{dt}}=V_{k p, f 6} \cdot \mathrm{Cdc} 6-\left(k_{p p, f 6} \cdot \frac{\mathrm{Cdc} 14}{\operatorname{mass}}+k_{d 3, f 6}\right) \cdot \mathrm{Cdc} 6 \mathrm{P} \\
& +V_{d, b 2} \cdot \mathrm{F} 2 \mathrm{P}+V_{d, b 5} \cdot \mathrm{F} 5 \mathrm{P}+k_{g} \cdot \mathrm{Cdc} 6 \mathrm{P}
\end{aligned}
$$

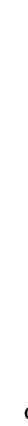




$$
\begin{aligned}
& \frac{\mathrm{d} \mathrm{Cdc} 14}{\mathrm{dt}}=k_{s, 14} \cdot \mathrm{mass} \cdot \mathrm{mCdc} 14-k_{d, 14} \cdot \mathrm{Cdc} 14 \\
& +k_{d, n e t} \cdot(\mathrm{RENT}+\mathrm{RENTP})+k_{d i, r e n t} \cdot \mathrm{RENT} \\
& +k_{d i, r e n t p} \cdot \mathrm{RENTP}+k_{g} \cdot \mathrm{Cdc} 14 \\
& -\left(k_{a s, \text { rent }} \cdot \frac{\text { Net } 1}{\operatorname{mass}}+k_{a s, \text { rentp }} \cdot \frac{\text { Net1P }}{\operatorname{mass}}\right) \cdot \operatorname{Cdc} 14 \\
& \frac{\mathrm{d} \text { Net1T }}{\mathrm{dt}}=k_{s, n e t} \cdot \operatorname{mass} \cdot \mathrm{mNet} 1-k_{d, n e t} \cdot \operatorname{Net} 1 \mathrm{~T}+k_{g} \cdot \operatorname{Net} 1 \mathrm{~T} \\
& \frac{\mathrm{d} \mathrm{Net} 1}{\mathrm{dt}}=k_{s, \text { net }} \cdot \operatorname{mass} \cdot \operatorname{mNet} 1-k_{d, \text { net }} \cdot \operatorname{Net} 1+k_{d, 14} \cdot \mathrm{RENT} \\
& +k_{d i, r e n t} \cdot \operatorname{RENT}-k_{a s, r e n t} \cdot \frac{\mathrm{Cdc} 14 \cdot \mathrm{Net} 1}{\operatorname{mass}} \\
& +V_{p p, n e t} \cdot \operatorname{Net} 1 \mathrm{P}-V_{k p, n e t} \cdot \operatorname{Net} 1+k_{g} \cdot \operatorname{Net} 1 \\
& \frac{\mathrm{d} \mathrm{RENT}}{\mathrm{dt}}=-\left(k_{d, 14}+k_{d, n e t}\right) \cdot \mathrm{RENT}-k_{d i, r e n t} \cdot \mathrm{RENT} \\
& +k_{a s, r e n t} \cdot \frac{\mathrm{Cdc} 14 \cdot \mathrm{Net} 1}{\operatorname{mass}}+V_{p p, n e t} \cdot \mathrm{RENTP} \\
& -V_{k p, n e t} \cdot \mathrm{RENT}+k_{g} \cdot \mathrm{RENT} \\
& \frac{\mathrm{d} \mathrm{Pds} 1}{\mathrm{dt}}=k_{s, p 1} \cdot \mathrm{mPds} 1+k_{d i, e s p} \cdot \mathrm{PE} \\
& -\left(V_{d, p d s}+k_{a s, e s p} \cdot \frac{\mathrm{Esp} 1}{\mathrm{mass}}\right) \cdot \mathrm{Pds} 1+k_{g} \cdot \operatorname{Pds} 1 \\
& \frac{\mathrm{d} \operatorname{Esp} 1}{\mathrm{dt}}=-k_{a s, e s p} \cdot \frac{\mathrm{Pds} 1 \cdot \operatorname{Esp} 1}{\operatorname{mass}}+\left(k_{d i, e s p}+V_{d, p d s}\right) \cdot \mathrm{PE} \\
& +k_{g} \cdot \operatorname{Esp} 1 \\
& \frac{\mathrm{d} \mathrm{ORI}}{\mathrm{dt}}=k_{s, o r i} \cdot\left(e_{\text {ori }, b 5} \cdot \mathrm{Clb} 5+e_{\text {or } i, b 2} \cdot \mathrm{Clb} 2\right) \\
& -k_{d, \text { ori }} \cdot \mathrm{ORI}+k_{g} \cdot \mathrm{ORI} \\
& \frac{\mathrm{d} \mathrm{BUD}}{\mathrm{dt}}=k_{s, b u d} \cdot\left(e_{b u d, n 2} \cdot \mathrm{Cln} 2+e_{\text {bud,n } 3} \cdot \mathrm{Cln} 3\right. \\
& \left.+e_{b u d, b 5} \cdot \mathrm{Clb} 5\right)-k_{d, b u d} \cdot \mathrm{BUD}+k_{g} \cdot \mathrm{BUD} \\
& \frac{\mathrm{d} \mathrm{SPN}}{\mathrm{dt}}=k_{s, s p n} \cdot \frac{\mathrm{Clb} 2}{J_{s p n}+\frac{\mathrm{Clb} 2}{c_{c l b 2} \cdot \mathrm{mass}}}-k_{d, s p n} \cdot \mathrm{SPN}+k_{g} \cdot \mathrm{SPN} \\
& \frac{\mathrm{d} \text { Tem } 1 \mathrm{~T}}{\mathrm{dt}}=k_{s, t e m 1 t} \cdot \mathrm{mass} \cdot \mathrm{mTem} 1-k_{d, t e m 1 t} \cdot \operatorname{Tem} 1 \mathrm{~T} \\
& +k_{g} \cdot \mathrm{Tem} 1 \mathrm{~T} \\
& \frac{\mathrm{d} \operatorname{Cdc} 15 \mathrm{~T}}{\mathrm{dt}}=k_{s, c d c 15 t} \cdot \operatorname{mass} \cdot \operatorname{mCdc} 15-k_{d, c d c 15 t} \cdot \operatorname{Cdc} 15 \mathrm{~T} \\
& +k_{g} \cdot \mathrm{Cdc} 15 \mathrm{~T} \\
& \frac{\mathrm{d} \operatorname{Esp} 1 \mathrm{~T}}{\mathrm{dt}}=k_{s, e s p 1 t} \cdot \operatorname{mass} \cdot \operatorname{mEsp} 1-k_{d, e s p 1 t} \cdot \operatorname{Esp} 1 \mathrm{~T} \\
& +k_{g} \cdot \operatorname{Esp} 1 \mathrm{~T} \\
& \frac{\mathrm{d} \mathrm{SBFT}}{\mathrm{dt}}=k_{s, s b f t} \cdot \mathrm{mass} \cdot \mathrm{mSBF}-k_{d, s b f t} \cdot \mathrm{SBFT}+k_{g} \cdot \mathrm{SBFT} \\
& \frac{\mathrm{d} \mathrm{MBFT}}{\mathrm{dt}}=k_{s, m b f t} \cdot \operatorname{mass} \cdot \mathrm{mMBF}-k_{d, m b f t} \cdot \mathrm{MBFT} \\
& +k_{g} \cdot \mathrm{MBFT} \\
& \frac{\mathrm{d} \mathrm{Mcm} 1 \mathrm{~T}}{\mathrm{dt}}=k_{s, m c m 1 t} \cdot \operatorname{mass} \cdot \mathrm{mMcm} 1-k_{d, m c m 1 t} \cdot \mathrm{Mcm} 1 \mathrm{~T} \\
& +k_{g} \cdot \operatorname{Mcm} 1 \mathrm{~T} \\
& \frac{\mathrm{d} \mathrm{APC}}{\mathrm{dt}}=k_{s, a p c t} \cdot \mathrm{mass} \cdot \mathrm{mAPC}-k_{d, a p c t} \cdot \mathrm{APC}+k_{g} \cdot \mathrm{APC}
\end{aligned}
$$

Molecule numbers of several proteins in this model are calculated according to algebraic equations. For protein SBF, $\mathrm{MBF}$ and Mcm1, their molecule numbers are regulated by a nonlinear function, the "Goldbeter-Koshland function" $G\left(V_{a}, V_{i}, J_{a}, J_{i}\right)$. There are also some variables needed to be computed which serve as reaction rates. Concentrations of some proteins are adopted in these variables. Let $\mathrm{P}$ be the number of molecules of a protein. The concentration of $\mathrm{P}$ is $[\mathrm{P}]=\mathrm{P} /\left(c_{p} \cdot\right.$ mass $)$, where $c_{p}$ is a constant which can be found in the table of parameters. Equations and definitions are given as follows.

$$
\begin{aligned}
& \mathrm{Cln} 3=\frac{C_{0} \cdot D_{n 3} \cdot \mathrm{mass}^{2}}{J_{n 3}+D_{n 3} \cdot \mathrm{mass}} \\
& \mathrm{Bck} 2=B_{0} \cdot \text { mass }^{2} \\
& \mathrm{Sic} 1 \mathrm{~T}=\mathrm{Sic} 1+\mathrm{Sic} 1 \mathrm{P}+\mathrm{C} 2+\mathrm{C} 2 \mathrm{P}+\mathrm{C} 5+\mathrm{C} 5 \mathrm{P} \\
& \mathrm{Cdc} 6 \mathrm{~T}=\mathrm{Cdc} 6+\mathrm{Cdc} 6 \mathrm{P}+\mathrm{F} 2+\mathrm{F} 2 \mathrm{P}+\mathrm{F} 5+\mathrm{F} 5 \mathrm{P} \\
& \mathrm{RENTP}=\mathrm{Cdc} 14 \mathrm{~T}-\mathrm{RENT}-\mathrm{Cdc} 14 \\
& \text { Net1P }=\text { Net1T }- \text { Net } 1-\text { Cdc14T }+ \text { Cdc14 } \\
& \mathrm{PE}=\mathrm{Esp} 1 \mathrm{~T}-\mathrm{Esp} 1 \\
& \mathrm{SBF}=G\left(V_{a, s b f}, V_{i, s b f}, J_{a, s b f}, J_{i, s b f}\right) \cdot \mathrm{SBFT} \\
& \mathrm{MBF}=G\left(V_{a, s b f}, V_{i, s b f}, J_{a, s b f}, J_{i, s b f}\right) \cdot \mathrm{MBFT} \\
& \mathrm{Mcm} 1=G\left(k_{a, m c m} \cdot \frac{\mathrm{Clb} 2}{\mathrm{mass}}, k_{i, m c m}, J_{a, m c m}, J_{i, m c m}\right) \cdot \mathrm{Mcm} 1 \mathrm{~T} \\
& V_{a, s b f}=k_{a, s b f}\left(e_{s b f, n 2} \cdot[\mathrm{Cln} 2]+e_{s b f, n 3}([\mathrm{Cln} 3]+[\mathrm{Bck} 2])\right. \\
& \left.+e_{s b f, b 5} \cdot[\mathrm{Clb} 5]\right) \\
& V_{i, s b f}=k_{i, s b f}^{\prime}+k_{i, s b f}^{\prime \prime} \cdot[\mathrm{Clb} 2] \\
& V_{d, b 5}=k_{d, b 5}^{\prime}+k_{d, b 5}^{\prime \prime} \cdot[\mathrm{Cdc} 20 \mathrm{~A}] \\
& V_{d, b 2}=k_{d, b 2}^{\prime}+k_{d, b 2}^{\prime \prime} \cdot[\mathrm{Cdh} 1]+k_{d, b 2 p} \cdot[\mathrm{Cdc} 20 \mathrm{~A}] \\
& V_{k p, c 1}=k_{d 1, c 1}+\frac{k_{d 2, c 1}}{J_{d 2, c 1}+[\operatorname{Sic} 1 \mathrm{~T}]}\left(e_{c 1, n 3} \cdot[\mathrm{Cln} 3]+e_{c 1, k 2} \cdot[\mathrm{Bck} 2]\right. \\
& \left.+e_{c 1, n 2} \cdot[\mathrm{Cln} 2]+e_{c 1, b 5} \cdot[\mathrm{Clb} 5]+e_{c 1, b 2} \cdot[\mathrm{Clb} 2]\right) \\
& V_{k p, f 6}=k_{d 1, f 6}+\frac{k_{d 2, f 6}}{J_{d 2, f 6}+[\mathrm{Cdc} 6 \mathrm{~T}]}\left(e_{f 6, n 3} \cdot[\mathrm{Cln} 3]+e_{f 6, k 2} \cdot[\mathrm{Bck} 2]\right. \\
& \left.+e_{f 6, n 2} \cdot[\mathrm{Cln} 2]+e_{f 6, b 5} \cdot[\mathrm{Clb} 5]+e_{f 6, b 2} \cdot[\mathrm{Clb} 2]\right) \\
& V_{a, c d h}=k_{a, c d h}^{\prime}+k_{a, c d h}^{\prime \prime} \cdot[\mathrm{Cdc} 14] \\
& V_{i, c d h}=k_{i, c d h}^{\prime}+k_{i, c d h}^{\prime \prime}\left(e_{c d h, n 3} \cdot[\mathrm{Cln} 3]+e_{c d h, n 2} \cdot[\mathrm{Cln} 2]\right. \\
& \left.+e_{c d h, b 2} \cdot[\mathrm{Clb} 2]+e_{c d h, b 5} \cdot[\mathrm{Clb} 5]\right) \\
& V_{p p, n e t}=k_{p p, n e t}^{\prime}+k_{p p, n e t}^{\prime \prime} \cdot[\mathrm{Cdc} 55] \\
& V_{k p, n e t}=\left(k_{k p, n e t}^{\prime}+k_{k p, n e t}^{\prime \prime} \cdot[\mathrm{Cdc} 15]\right) \cdot \operatorname{mass} \\
& V_{d, p p x}=k_{d, p p x}^{\prime}+k_{d, p p x}^{\prime \prime}\left(J_{20, p p x}+[\mathrm{Cdc} 20 \mathrm{~A}]\right) \cdot \frac{J_{p d s}}{J_{p d s}+[\mathrm{Pds} 1]} \\
& V_{d, p d s}=k_{d 1, p d s}^{\prime}+k_{d 2, p d s}^{\prime \prime} \cdot[\mathrm{Cdc} 20 \mathrm{~A}]+k_{d 3, p d s}^{\prime \prime} \cdot[\mathrm{Cdh} 1]
\end{aligned}
$$

Reactions and their propensities related to mRNAs are listed in Table 7.

\section{B. PARAMETERS}

Reaction rates and constants used in the hybrid stochastic model are listed in Table 8 . In this model, the values of three rate constants are controlled by concentrations of some proteins.

- $k_{\text {mad } 2}=8$ for $[\mathrm{ORI}]>1$ and $[\mathrm{SPN}]<1$; otherwise 0.01 .

- $k_{\text {bud } 2}=1$ for $[\mathrm{ORI}]>1$ and $[\mathrm{SPN}]<1$; otherwise 0.2 .

- $k_{l t e 1}=1$ for $[\mathrm{SPN}]>1$ and $[\mathrm{Clb} 2]>1$; otherwise 0.1 . 
Table 7: SSA System for mRNAs of The Hybrid Model of The Budding Yeast Cell Cycle

\begin{tabular}{|c|c|c|c|}
\hline Reaction & Propensity Function & Reaction & Propensity Function \\
\hline$\phi \rightarrow \mathrm{mCdh} 1$ & $k_{s, m c d h 1}$ & $\mathrm{mCdh} 1 \rightarrow \phi$ & $k_{d, m c d h 1} \cdot \mathrm{mCdh} 1$ \\
\hline$\phi \rightarrow \mathrm{mTem} 1$ & $k_{s, m t e m 1}$ & $\mathrm{mTem} 1 \rightarrow \phi$ & $k_{d, m t e m 1} \cdot \mathrm{mTem} 1$ \\
\hline$\phi \rightarrow \mathrm{mCdc} 15$ & $k_{s, m c d c 15}$ & $\mathrm{mCdc} 15 \rightarrow \phi$ & $k_{d, m c d c 15} \cdot \mathrm{mCdc} 15$ \\
\hline$\phi \rightarrow \mathrm{mCdc} 14$ & $k_{s, m c d c 14}$ & $\mathrm{mCdc} 14 \rightarrow \phi$ & $k_{d, m c d c 14} \cdot \mathrm{mCdc} 14$ \\
\hline$\phi \rightarrow \mathrm{mNet} 1$ & 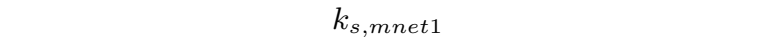 & $\mathrm{mNet} 1 \rightarrow \phi$ & $k_{d, m n e t 1} \cdot \operatorname{mNet} 1$ \\
\hline$\phi \rightarrow \mathrm{mCdc} 55$ & $k_{s, m c d c 55}$ & $\mathrm{mCdc} 55 \rightarrow \phi$ & $k_{d, m c d c 55} \cdot \mathrm{mCdc} 55$ \\
\hline$\phi \rightarrow \mathrm{mEsp} 1$ & $k_{s, m e s p 1}$ & $\mathrm{mEsp} 1 \rightarrow \phi$ & $k_{d, m e s p 1} \cdot \mathrm{mEsp} 1$ \\
\hline$\phi \rightarrow \mathrm{mSBF}$ & $k_{s, m s b f}$ & $\mathrm{mSBF} \rightarrow \phi$ & $k_{d, m s b f} \cdot \mathrm{mSBF}$ \\
\hline$\phi \rightarrow \mathrm{mMBF}$ & $k_{s, m m b f}$ & $\mathrm{mMBF} \rightarrow \phi$ & $k_{d, m m b f} \cdot \mathrm{mMBF}$ \\
\hline$\phi \rightarrow \mathrm{mMcm} 1$ & $k_{s, m m c m 1}$ & $\mathrm{mMcm} 1 \rightarrow \phi$ & $k_{d, m m c m 1} \cdot \mathrm{mMcm} 1$ \\
\hline$\phi \rightarrow \mathrm{mAPC}$ & $k_{s, \text { mapc }}$ & $\mathrm{mAPC} \rightarrow \phi$ & $k_{d, \text { mapc }} \cdot \mathrm{mAPC}$ \\
\hline$\phi \rightarrow \mathrm{mCln} 2$ & $k_{s, m c l n 2}\left(k_{s, n 2}^{\prime} \cdot \operatorname{mass}+k_{s, n 2}^{\prime \prime} \cdot \mathrm{SBF}\right)$ & $\mathrm{mCln} 2 \rightarrow \phi$ & $k_{d, m c l n} 2 \cdot \mathrm{mCln} 2$ \\
\hline$\phi \rightarrow \mathrm{mClb} 5$ & $k_{s, m c l b 5}\left(k_{s, b 5}^{\prime} \cdot \operatorname{mass}+k_{s, b 5}^{\prime \prime} \cdot \mathrm{MBF}\right)$ & $\mathrm{mClb} 5 \rightarrow \phi$ & $k_{d, m c l b 5} \cdot \mathrm{mClb} 5$ \\
\hline$\phi \rightarrow \mathrm{mClb} 2$ & $k_{s, m c l b 2}\left(k_{s, b 2}^{\prime} \cdot \operatorname{mass}+k_{s, b 2}^{\prime \prime} \cdot \mathrm{Mcm} 1\right)$ & $\mathrm{mClb} 2 \rightarrow \phi$ & $k_{d, m c l b 2} \cdot \mathrm{mClb} 2$ \\
\hline$\phi \rightarrow \mathrm{mSic} 1$ & $k_{s, m s i c 1}\left(k_{s, c 1}^{\prime} \cdot \operatorname{mass}+k_{s, c 1}^{\prime \prime \prime} \cdot\right.$ Swi 5$)$ & $\operatorname{mSic} 1 \rightarrow \phi$ & $k_{d, m s i c 1} \cdot \mathrm{mSic} 1$ \\
\hline$\phi \rightarrow \mathrm{mCdc} 6$ & $k_{s, m n c d c 6}\left(k_{s, f 6}^{\prime} \cdot \operatorname{mass}+k_{s, f 6}^{\prime \prime} \cdot \mathrm{Swi} 5+k_{s, f 6}^{\prime \prime \prime} \cdot \mathrm{SBF}\right)$ & $\mathrm{mCdc} 6 \rightarrow \phi$ & $k_{d, m c d c 6} \cdot \mathrm{mCdc} 6$ \\
\hline$\phi \rightarrow \mathrm{mSwi} 5$ & $k_{s, m s w i 5}\left(k_{s, s w i}^{\prime} \cdot \operatorname{mass}+k_{s, s w i}^{\prime \prime} \cdot \mathrm{Mcm} 1\right)$ & $\mathrm{mSwi} 5 \rightarrow \phi$ & $k_{d, m s w i 5} \cdot \mathrm{mSwi} 5$ \\
\hline$\phi \rightarrow \operatorname{mCdc} 20$ & $k_{s, m c d c 20}\left(k_{s, 20}^{\prime} \cdot \operatorname{mass}+k_{s, 20}^{\prime \prime} \cdot \mathrm{Mcm} 1\right)$ & $\mathrm{mCdc} 20 \rightarrow \phi$ & $k_{d, m c d c 20} \cdot \mathrm{mCdc} 20$ \\
\hline$\phi \rightarrow \mathrm{mPds} 1$ & $k_{s, m p d s 1}\left(k_{s, p d s}^{\prime} \cdot \operatorname{mass}+k_{s 1, p d s}^{\prime \prime} \cdot \mathrm{SBF}+k_{s 2, p d s}^{\prime \prime} \cdot \mathrm{Mcm} 1\right)$ & $\mathrm{mPds} 1 \rightarrow \phi$ & $k_{d, m p s d 1} \cdot \mathrm{mPds}$ \\
\hline
\end{tabular}

Table 8: Parameter Values

\begin{tabular}{|c|c|c|c|c|c|}
\hline$k_{s, n 2}=14.35$ & $k_{d, n 2}=0.12$ & $k_{s, b 5}=0.9165$ & $\bar{k}_{d 3, c 1}=1$ & $\bar{c}_{d i, b 5}=0.06$ & $k_{d 3, f 6}=1$ \\
\hline$k_{d i, f 5}=0.01$ & $k_{a s, b 5}=0.0668$ & $k_{a s, f 5}=1.34 \mathrm{e}-5$ & $k_{s, b 2}=6.668$ & $k_{d i, b 2}=0.05$ & $k_{d i, f 2}=0.5$ \\
\hline$k_{a s, b 2}=0.0668$ & $k_{a s, f 2}=0.02$ & $k_{s, s 1}=33.48$ & $k_{p p, c 1}=0.0137$ & $k_{s, c 6}=20$ & $k_{p p, f 6}=0.0137$ \\
\hline$k_{s, s 5}=6.479$ & $k_{d, s w i}=0.08$ & $k_{a, s w i}=6.849 \mathrm{e}-3$ & $k_{i, s w i}=6.678 \mathrm{e}-5$ & $k_{a, a p c}=1.336 \mathrm{e}-4$ & $k_{i, a p c}=0.15$ \\
\hline$k_{d, 20}=0.3$ & $k_{a, 20}^{\prime}=0.05$ & $k_{a, 20}^{\prime \prime}=7.285 \mathrm{e}-4$ & $k_{s, c d h}=1.7827$ & $k_{s_{c} 20}=259$ & $k_{d, c d h}=0.01$ \\
\hline$k_{a, 15}^{\prime}=1.78 \mathrm{e}-6$ & $k_{a, 15}^{\prime \prime}=8.9 \mathrm{e}-4$ & $k_{a, 15}^{\prime \prime \prime \prime}=3.425 \mathrm{e}-6$ & $k_{i, 15}=0.5$ & $k_{s, 14}=5.309$ & $k_{d, 14}=0.1$ \\
\hline$k_{d, n e t}=0.03$ & $k_{d i, \text { rent }}=1$ & $k_{d i, \text { rentp }}=2$ & $k_{a s, \text { rent }}=0.6849$ & $k_{a s, \text { rentp }}=3.425 \mathrm{e}-3$ & $k_{s, n e t}=3.925$ \\
\hline$k_{s, p p x}=98.05$ & $k_{s, p 1}=0.6457$ & $k_{d i, e s p}=0.5$ & $k_{a s, e s p}=1.214$ & $k_{s, \text { ori }}=0.3333$ & $k_{d, \text { ori }}=0.06$ \\
\hline$k_{s, b u d}=0.2$ & $k_{d, b u d}=0.06$ & $k_{s, s p n}=0.01667$ & $k_{d, s p n}=0.06$ & $k_{s, t e m 1 t}=16.85$ & $k_{d, t e m 1 t}=0.0462$ \\
\hline$k_{s, c d c 15 t}=7.118$ & $k_{d, c d c 15 t}=0.0462$ & $k_{s, e s p 1 t}=0.5783$ & $k_{d, e s p 1 t}=0.0462$ & $k_{s, s b f t}=3.3521$ & $k_{d, s b f t}=0.0462$ \\
\hline$k_{s, m b f t}=2.8085$ & $k_{d, m b f t}=0.0462$ & $k_{s, \text { apct }}=1.812$ & $k_{d, \text { apct }}=0.0462$ & $k_{a, s b f}=0.38$ & $k_{i, s b f}^{\prime}=0.6$ \\
\hline$k_{i, s b f}^{\prime \prime}=8$ & $k_{d, b 5}^{\prime}=0.01$ & $k_{d, b 2}^{\prime}=0.003$ & $k_{d, b 2}^{\prime \prime}=0.4$ & $k_{d, b 2 p}=0.15$ & $k_{d 1, c 1}=0.01$ \\
\hline$k_{d 2, c 1}=1$ & $k_{d, b 5}^{\prime \prime}=0.16$ & $k_{d 1, f 6}=0.01$ & $k_{d 2, f 6}=1$ & $k_{a, c d h}^{\prime}=0.01$ & $k_{a, c d h}^{\prime \prime}=0.8$ \\
\hline$k_{i, c d h}^{\prime}=0.001$ & $k_{i, c d h}^{\prime \prime}=0.08$ & $k_{p p, n e t}^{\prime}=0.05$ & $k_{p p, n e t}^{\prime \prime}=3$ & $k_{k p, \text { net }}^{\prime}=0.01$ & $k_{k p, n e t}^{\prime \prime \prime}=0.6$ \\
\hline$k_{d, p p x}^{\prime}=0.17$ & $k_{d, p p x}^{\prime \prime}=2$ & $k_{d 1, p d s}^{\prime}=0.01$ & $k_{d 2, p d s}^{\prime \prime}=0.2$ & $k_{d 3, p d s}^{\prime \prime}=0.04$ & $k_{s, n 2}^{\prime}=0$ \\
\hline$k_{s, n 2}^{\prime \prime \prime}=0.07371$ & $k_{s, b 5}^{\prime}=0.599$ & $k_{s, b 5}^{\prime \prime}=8.797 \mathrm{e}-3$ & $k_{s, b 2}^{\prime}=0.7487$ & $k_{s, b 2}^{\prime \prime}=0.003$ & $k_{s, c 1}^{\prime}=8.9839$ \\
\hline$k_{s, c 1}^{\prime \prime}=0.1252$ & $k_{s, f 6}^{\prime}=17.9698$ & $k_{s, f 6}^{\prime \prime}=0.1252$ & $k_{s, f 6}^{\prime \prime \prime}=0.005897$ & $k_{s, s w i}^{\prime}=3.5877$ & $k_{s, s w i}^{\prime \prime}=0.00575$ \\
\hline $\begin{array}{l}k_{s, 20}^{\prime}=11.2311 \\
k_{i}=0.15\end{array}$ & $k_{s, 20}^{\prime \prime}=0.1125$ & $k_{s, p d s}^{\prime}=0$ & $k_{s 1, p d s}^{\prime \prime}=0.002432$ & $k_{s 2, p d s}^{\prime \prime}=2.269 \mathrm{e}-4$ & $k_{a, m c m}=0.008$ \\
\hline $\begin{array}{l}k_{i, m c m}=0.10 \\
k_{s, m C d h 1}=0.9704\end{array}$ & $k_{d, m C d h 1}=0.1386$ & $k_{s, m T e m 1}=0.4270$ & $m 1=0.1386$ & $k_{s, m C d c 15}=0.4492$ & $k_{d, m C d c 15}=0.1386$ \\
\hline$k_{s, m C d c 14}=1.5249$ & $k_{d, m C d c 14}=0.1386$ & $k_{s, m N e t 1}=0.5413$ & $k_{d, m N e t 1}=0.0866$ & $k_{s, m C d c 55}=0.9704$ & $k_{d, m C d c 55}=0.1386$ \\
\hline$k_{s, m E s p 1}=0.3257$ & $k_{d, m E s p 1}=0.0990$ & $k_{s, m S B F}=0.9407$ & $k_{d, m S B F}=0.1386$ & $k_{s, m M B F}=0.9704$ & $k_{d, m M B F}=0.1386$ \\
\hline$k_{s, m M c m 1}=0.8248$ & $k_{d, m M c m 1}=0.1386$ & $k_{s, m A P C}=0.9704$ & $k_{d, m A P C}=0.1386$ & $k_{s, m C l n 2}=0.0239$ & $k_{d, m C l n 2}=0.2310$ \\
\hline$k_{s, m C l b 5}=0.1747$ & $k_{d, m C l b 5}=0.1386$ & $k_{s, m C l b 2}=0.0433$ & $k_{d, m C l b 2}=0.3466$ & $k_{s, m S i c 1}=0.005172$ & $k_{d, m S i c 1}=0.1386$ \\
\hline$k_{s, m C d c 6}=0.005334$ & $k_{d, m C d c 6}=0.1386$ & $k_{s, m S w i 5}=0.01925$ & $k_{d, m S w i 5}=0.1386$ & $k_{s, m C d c 20}=5.886 \mathrm{e}-4$ & $k_{d, m C d c 20}=0.1386$ \\
\hline$k_{s, m P d s 1}=0.2372$ & $k_{d, m P d s 1}=0.1386$ & & & & \\
\hline$c_{a p c}=274.5$ & $c_{c d h 1}=1248$ & $c_{t e m 1}=1123$ & $c_{c l b 2}=748.7$ & $c_{c \ln 2}=249.6$ & $c_{c \ln 3}=2496$ \\
\hline$c_{b c k 2}=2496$ & $c_{c l b 5}=748.7$ & $c_{c d c 20}=1872$ & $c_{s i c 1}=748.7$ & $c_{c d c 6}=748.7$ & $c_{c d c 14}=292$ \\
\hline$c_{c d c 55}=6863$ & $c_{c d c 15}=499$ & $c_{p d s 1}=41.18$ & $c_{\text {ori }}=124.9$ & $c_{s p n}=124.9$ & \\
\hline$B_{0}=134.77$ & $D_{n 3}=1$ & $C_{0}=998.3$ & $k_{e z}=0.3$ & $k_{e z 2}=0.2$ & \\
\hline$J_{a, a p c}=0.1$ & $J_{i, a p c}=0.1$ & $J_{a, c d h}=0.03$ & $J_{i, c d h}=0.03$ & $J_{a, t e m}=0.1$ & $J_{i, t e m}=0.1$ \\
\hline$J_{s p n}=0.14$ & $J_{n 3}=6$ & $J_{a, m c m}=0.1$ & $J_{i, m c m}=0.1$ & $J_{d 2, c 1}=0.05$ & $J_{d 2, f 6}=0.05$ \\
\hline$J_{20, p p x}=0.15$ & $J_{p d s}=0.04$ & $J_{a, s b f}=0.01$ & $J_{i, s b f}=0.01$ & & \\
\hline$e_{\text {ori }, b 5}=0.9$ & $e_{o r i, b 2}=0.45$ & $e_{b u d, n 2}=0.125$ & $e_{b u d, n 3}=2.5 \mathrm{e}-3$ & $e_{b u d, b 5}=0.1667$ & $e_{s b f, n 2}=2$ \\
\hline$e_{s b f, n 3}=10$ & $e_{s b f, b 5}=2$ & $e_{c 1, n 3}=0.3$ & $e_{c 1, k 2}=0.03$ & $e_{c 1, n 2}=0.06$ & $e_{c 1, b 5}=0.1$ \\
\hline$e_{c 1, b 2}=0.45$ & $e_{f 6, n 3}=0.3$ & $e_{f 6, k 2}=0.03$ & $e_{f 6, n 2}=0.06$ & $e_{f 6, b 5}=0.1$ & $e_{f 6, b 2}=0.55$ \\
\hline$e_{c d h, n 3}=0.25$ & $e_{c d h, n 2}=0.4$ & $e_{c d h, b 2}=1.2$ & $e_{c d h, b 5}=8$ & & \\
\hline
\end{tabular}

